\title{
Variability and Genetic Structure in a Commercial Field of Tequila Plants, Agave tequilana Weber (Agavaceae)
}

\author{
Martha Isabel Torres-Moran, Ana Paulina Velasco-Ramirez, \\ Salvador Antonio Hurtado-de la Pena, Andres Rodriguez-Garcia and Salvador Mena-Munguia \\ Departamento de Produccion Agricola, Universidad de Guadalajara, \\ Centro Universitario de Ciencias Biológicas y Agropecuarias. Km.15.5 Carr. \\ Guadalajara-Nogales, CP 45110. Las Agujas, Nextipac, Zapopan, Jalisco, Mexico
}

Received 2012-06-17, Revised 2013-01-18; Accepted 2013-02-22

\begin{abstract}
Crops of the tequila plant (Agave tequilana) are produced mainly from offshoots of mother plants in established commercial fields. This propagation method is significant, as it is believed that it facilitates the spread of disease because of the crop's low genetic variability and is also necessary because it is regulate the use of just that variety in tequila industry. Different levels of genetic variability have been reported for A. tequilana and so we tested individuals from representative cultivation zones to determine the actual variability in fields and to assess the genetic structure of populations in commercial plantations. Four additional Agave spp. were used as a control group while Fourcrea spp. individuals were used as an external group. Morphological traits and molecular markers were analyzed. The differences between $A$. tequilana individuals collected from southern Jalisco state and those collected in the principal Denomination of Origin zone confirmed the existence of different genotypes, which were conserved in different regions by asexual propagation. Leaf length, plant height and number of leaves were the most significant variables that explained the variability within the $A$. tequilana group. At the molecular level, we found genetic differentiation with a minimum similarity of 0.253 (Jaccard's coefficient) and genetic structure analysis indicated five groups with significant genotypic differences. Genetic structure analysis, grouped accessions according to the dispersion of plant material from the initial sites of cultivation. These results might facilitate the correlation of different groups with crop yield or tequila quality and the establishment of elite lines for breeding programs. It is recommendable in a future, to determinate the different levels of inulines produced by each detected group.
\end{abstract}

Keywords: Molecular Markers, ISTR, Morphological Traits, Asexual Propagation

\section{INTRODUCTION}

Tequila is an alcoholic beverage that is known throughout the world. The Mexican tequila industry is important and complex because it supports the economy of a large region. In recent decades, there has been a revolution in the entire process used for producing tequila. First, the agave plant material must be exclusively Agave tequilana Weber var. azul. An official standard, the Norma Oficial Mexicana NOM006SFI-1994, regulates the process and determines the places or regions where Denomination of Origin tequila can be produced. Second, the agronomic management of agave culture has changed greatly. Most tequila crops are cultured initially from agave offshoots produced by mother plants in commercial fields, which

Corresponding Author: Martha Isabel Torres-Moran, Departamento de Produccion Agricola, Universidad de Guadalajara, Centro Universitario de Ciencias Biológicas y Agropecuarias. Km.15.5 Carr. Guadalajara-Nogales, CP 45110. Las Agujas, Nextipac, Zapopan, Jalisco, México 
facilitates the spread of diseases (Esqueda et al., 2011) because asexual propagation leads to lower genetic variability (Cedeno and Alvarez-Jacobs, 2000; Colunga-Garcia and Zizumbo-Villareal, 2007). Indeed, low levels of genetic variability were reported 10 years ago (Gil-Vega et al., 2001). The producers and industry maintain a uniform agave phenotype via asexual reproduction using offshoots and bulbils. Agave producers also use seeds, but seeds and bulbils are used rarely in commercial plantations, although they might be used in breeding programs (Piven et al., 2001). Relatively low levels of genetic diversity have been found in many asexually produced populations, but it is important to note that not all asexual populations are genetically uniform. Thus, offshoots provide a certain level of agave uniformity, but different levels of genetic variability have been detected in A. tequilana (GilVega et al., 2006; Torres-Moran et al., 2010) and several other Agave spp. using molecular tools (MagdubMendez, 2000; Demey et al., 2004; Infante et al., 2007; Sanchez-Teyer et al., 2009). Other studies have also reported variability in the morphological characteristics of the Agave genus. Colunga-Garcia and May-Pat (1997) demonstrated that there was a discontinuity in the morphological variation pattern of $A$. fourcroydes (henequen) in uniform conditions, according to Principal Components Analysis (PCA) and Analyses of Variance based on vegetative characteristics. Other morphologic characteristics and molecular markers have been used for the morphological and molecular characterization of $A$. tequilana and $A$. angustifolia, which are closely related species (Rodriguez-Garay et al., 2009; Vargas-Ponce et al., 2009). Different numbers of individuals were used to detect this variability, i.e., samples ranged from five to 42 individuals (Gil-Vega et al., 2001; Davila et al., 2007; Rodriguez-Garay et al., 2009; Vargas-Ponce et al., 2009). According to Nei (1978), an estimation of genetic distances in molecular data can be achieved with a sample of 10 individuals when the number of loci detected is $\geq 50$. However, considerably more individuals need to be examined at each locus if the number of loci is small. In this study, we estimated the variability using $100 \mathrm{~A}$. tequilana individuals in a crop field, which was established according to traditional production methods using offshoots acquired from different areas in the Denomination of Origin Zone (DOZ). Individuals were collected from representative cultivation zones and used to determine the variability that was actually present in the field and to assess the genetic structure of a commercial plantation population. We assessed morphological traits and Inverse Sequence Tagged Repeat (ISTR) molecular markers, which have been used previously to detect variability in the Agave genus (Infante et al., 2003; Torres-Moran et al., 2010). The identification of genetically different groups may facilitate the correlation of groups with yield and tequila quality, as well as the establishment of elite lines for breeding programs.

\section{MATERIALS AND METHODS}

\subsection{Plant Material}

One hundred $A$. tequilana Weber specimens were collected from 14 localities in the DOZ (Fig. 1) and established in commercial plantations. The samples were maintained at Centro Universitario de Ciencias Biológicas y Agropecuarias in Zapopan, Jalisco state, which is located within the DOZ. Measurements were made when individuals reached 3 years old. Ten individual specimens of $A$. americana L., A. maximiliana Baker and $A$. salmiana Otto ex. Salm Dyck and five individual specimens of $A$. angustifolia Haw were used as a control group (Fig. 2). Keys were used to describe the individual origins, as shown in Table 1. In the molecular marker analysis, a Fourcrea spp. group was also used to represent species from the Agavaceae family.

\subsection{Morphological Markers}

Morphological variables were measured for $100 \mathrm{~A}$. tequilana specimens and the comparison species. The variables quantified were: Number of leaves $(\mathrm{NH})$, plant height (AP), Diameter of cone (DT), Leaf length (LH), leaf width (AH) and Number of teeth per $10 \mathrm{~cm}(\mathrm{NE})$.

\subsection{DNA Isolation and Molecular Markers Application}

Leaf tissues were collected from the A. tequilana specimens and comparison groups. Total DNA was isolated from each individual using the $\mathrm{CTAB}$ procedure of Keb-Llanes et al. (2002). Retrotransposon fragments were amplified using the following primer pairs: FI/B6 (d-5' [GCA CTC CAC CAA GAA TAC C] 3'/d-3' [GGT TTC ACT TTG TCC TTA G]5') and F91/31 (d-5'[ATA TGG ACT TAA GCA AGC CA] 3'/d-3' [ATT CCC ATC TGC ACC AAT] ')'. PCR amplifications were performed according to the method of Torres-Moran et al. (2010), with $25 \mathrm{ng}$ of DNA in $20 \mu \mathrm{L}$ reaction volumes containing 1 unit of Taq DNA polymerase (Promega $\left.{ }^{\circledR}\right), 3 \mathrm{mM}$ $\mathrm{MgCl}_{2}, 0.3 \mu \mathrm{M}$ of each primer, $0.25 \mathrm{mM}$ of each dNTP and the buffer supplied with the enzyme. 
Martha Isabel Torres-Moran et al. / American Journal of Agricultural and Biological Sciences 8 (1): 44-53, 2013

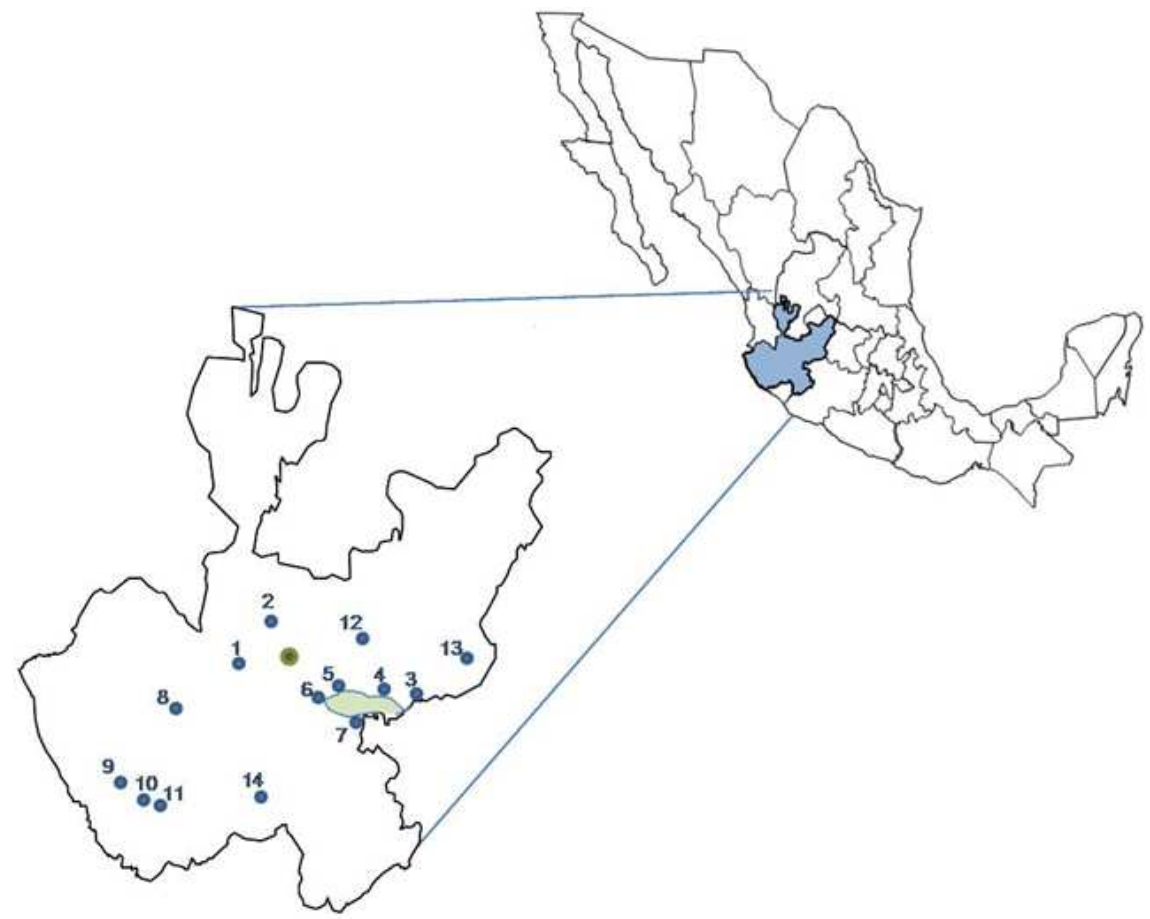

Fig. 1. Agave tequilana collection sites. 1: Ameca; 2: Arenal; 3: La Barca; 4: Ocotlán; 5: Chapala; 6: Jocotepec; 7: Tizapán el Alto; 8: Juchitlán; 9: Unión de Tula; 10: El Grullo; 11: El Limón; 12: Acatic; 13: Jesús María; 14: San Gabriel

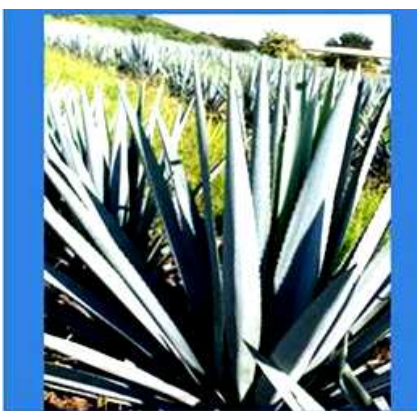

Agave tequilana (FAC) weber

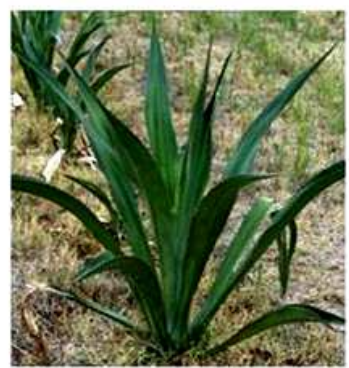

Furcraea sp (L) haw

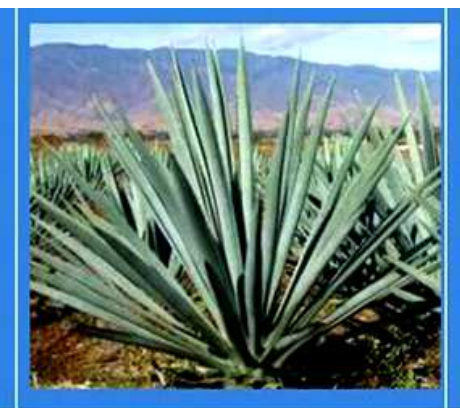

A. angustifolia

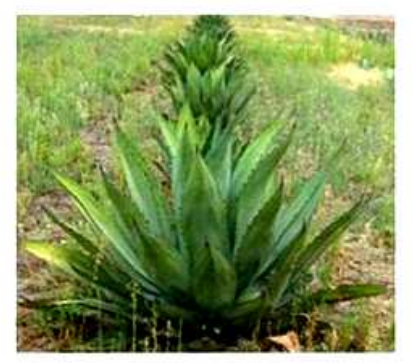

A.salmiana otto ex salm dy ck

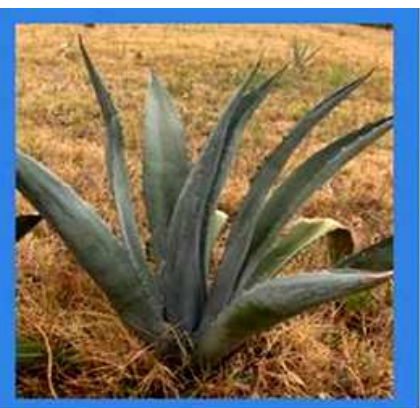

Agave amerocama L.

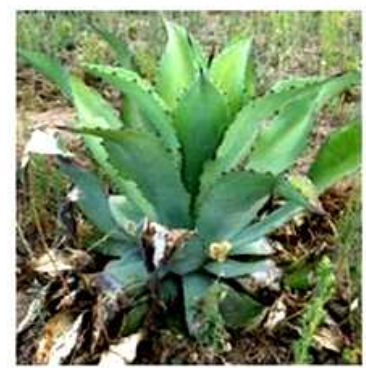

A. maximiliana (Berger) gemtry

Fig. 2. Phenotypic differences among species from the Agavaceae family 
Martha Isabel Torres-Moran et al. / American Journal of Agricultural and Biological Sciences 8 (1): 44-53, 2013

Table 1. Origin and identification keys for agave individuals from the control and reference groups used in the present study

\begin{tabular}{lll}
\hline Species & Origin & Individual keys \\
\hline Agave tequilana & Ameca, Jal. & A_azul AM 1 to 12 \\
Agave tequilana & Acatic, Jal. & A_azul AC 1 to 10 \\
Agave tequilana & San Gabriel, Jal. & A_azul SG 1 to 3 \\
Agave tequilana & Unión de Tula, Jal. & A_azul UT 1 to 5 \\
Agave tequilana & Jesús María, Jal. & A_azul JM 1 to 3 \\
Agave tequilana & Juchitlán, Jal. & A_azul JU 1 to 7 \\
Agave tequilana & El Limón, Jal. & A_azul EL 1 to 10 \\
Agave tequilana & Tizapán, Jal & A_azul TI 1 to 8 \\
Agave tequilana & La Barca, Jal. & A_azul LB 1 to 7 \\
Agave tequilana & El Grullo, Jal. & A_azul EG 1 to 10 \\
Agave tequilana & Jocotepec, Jal. & A_azul JO 1 to 3 \\
Agave tequilana & Arenal, Jal. & A_azul AR 1 to 6* \\
Agave tequilana & Chapala, Jal. & A_azul CH 1 to 6 \\
Agave tequilana & Ocotlán, Jal. & A_azul OC 1 to 10 \\
Agave maximiliana & Mascota, Jal. & A_maxi MA 1 to 10 \\
Agave angustifolia & Nextipac, Jal. & A_angu NE 1 to 5 \\
Agave salmiana & Ahualulco, Jal. & A_salm AH 1 to 10 \\
Agave americana & San José de Gracia, Mich. & A_amer SJ 1 to 10 \\
Fourcrea spp. & & F_AH1 to 4 \\
\hline Agave from
\end{tabular}

Agave from representative DOZ

The PCR cycling conditions were $3 \mathrm{~min}$ at $95^{\circ} \mathrm{C}$, followed by 40 cycles of $30 \mathrm{~s}$ at $95^{\circ} \mathrm{C}$ and annealing at $45^{\circ} \mathrm{C}$ for 1 min, with extension at $72^{\circ} \mathrm{C}$ for 2 min and a final extension at $72^{\circ} \mathrm{C}$ for $10 \mathrm{~min}$. DNA amplification was performed using a Techne Flexigene ${ }^{\circledR}$ thermocycler. Amplification fragments were separated by electrophoresis using $6 \%$ polyacrylamide gels and stained with silver salts, according to the methods of Sanguinetti et al. (1994) and Sambrook and Russell (2001).

\subsection{Data Analysis}

The statistical analysis of variability within species used the classical BART test written in SAS code for the SAS program (SASI, 1994) and homogeneity of variances using the procedure DISCRIM, according to the methods of Morrison (1976). A cluster analysis was also performed based on the correlation matrix: $r_{i j}=$ $\left(\sum_{\mathrm{k}} \mathrm{x}_{\mathrm{kj}} \mathrm{x}_{\mathrm{ki}}\right) /\left(\sum_{\mathrm{k}} \mathrm{x}_{\mathrm{ki}}{ }^{2} \sum_{\mathrm{k}} \mathrm{x}_{\mathrm{kj}}{ }^{2}\right)^{1 / 2}$ where $\mathrm{ij}$ corresponds to the plants and $\mathrm{k}$ indicates the variables, which were standardized to a mean of zero and a variance of one in this study. Clustering was performed using the Unweighted Pair Group Method with Arithmetic Mean (UPGMA) in NTSYS 2.11 (Rohlf, 1994). The results were represented using a dendrogram. The PCA was represented using a biplot graph, as described by Rawlings (1988) and Sanchez (1995). To examine genetic structure a Bayesian cluster analysis using STRUCTURE software was performed (Pritchard et al.,
2000). This analysis estimates membership of each individual to a population $\mathrm{K}$ we selected, the admixture model and correlated allele frequencies with a burn-in period and MCMC of $10^{5}$ iterations. To verify the most probable number of cluster $(\mathrm{K})$, the method of Evanno et al. (2005) was following using a range of $\mathrm{K}$ from 2 to 8 .

\section{RESULTS}

\subsection{Morphological Markers}

The PCA indicated that the first two components explained $70 \%$ of the total variation observed. The first Component (C1) explained $45 \%$ and it was defined by the variables $\mathrm{AP}, \mathrm{LH}$ and $\mathrm{NH}$. The second Component (C2) explained $25 \%$ of the variability among groups and was defined by the variables AH and DT. The results are shown in Table 2.

Figure 3 shows that $A$. tequilana and $A$. angustifolia are located on the positive side of the biplot graph and both species belong to the Rigidae group with elongated stems and sword-shaped leaves. The variability and spatial location of this group were defined by LH, AP and $\mathrm{NH}$ and these species shared similar phenotypes. Dots represent individuals in Fig. 3 and they are dispersed according to the variables that group their components. It can be seen that the dispersion of the comparison groups was greater than that of $A$. tequilana. 
Martha Isabel Torres-Moran et al. / American Journal of Agricultural and Biological Sciences 8 (1): 44-53, 2013

Table 2. Principal components analysis eigenvector values for the morphological characters of $A$. tequilana and five species of Agavaceae

\begin{tabular}{|c|c|c|c|c|c|c|c|}
\hline Variable & Key & $\mathrm{C} 1$ & $\mathrm{C} 2$ & C3 & $\mathrm{C} 4$ & $\mathrm{C} 5$ & C6 \\
\hline Number of leaves & $\mathrm{NH}$ & 0.3600 & 0.1400 & 0.6400 & -0.6000 & -0.1500 & 0.170 \\
\hline Plant height & $\mathrm{AP}$ & 0.5800 & 0.0065 & 0.0350 & 0.0920 & 0.3600 & -0.710 \\
\hline Diameter of cone & DT & 0.2300 & 0.6200 & 0.1600 & 0.5900 & -0.4000 & 0.070 \\
\hline Leaf length & LH & 0.5600 & -0.1700 & -0.1800 & 0.2000 & 0.3700 & 0.670 \\
\hline Leaf width & $\mathrm{AH}$ & -0.3000 & 0.6400 & 0.0560 & -0.1100 & 0.6800 & 0.100 \\
\hline Number of spines & $\mathrm{NE}$ & -0.2500 & -0.3700 & 0.7100 & 0.4600 & 0.2500 & 0.020 \\
\hline Variation (\%) & & 0.4533 & 0.2530 & 0.1577 & 0.0887 & 0.0393 & 0.008 \\
\hline
\end{tabular}

Table 3. Estimation of variance for the morphological traits among five species of Agavaceae using Bartlett's test

\begin{tabular}{lcccccrr}
\hline Species & VNH & VAP & VDT & VLH & VAH & \multicolumn{1}{l}{ VNE } & \multicolumn{1}{l}{$\operatorname{logD}$} \\
\hline Agave tequilana & 87.490 & 0.020 & 20.8600 & 93.410 & 0.48000 & 1.21000 & 5.59000 \\
Agave salmiana & 83.600 & 0.010 & 83.1200 & 56.710 & 8.67000 & 1.38000 & 7.89000 \\
Agave maximiliana & 22.220 & 0.010 & 7.3900 & 46.490 & 3.11000 & 9.43000 & 3.96000 \\
Agave americana & 18.890 & 0.030 & 59.7900 & 131.880 & 5.38000 & 0.18000 & 3.21000 \\
Agave angustifolia & 26.800 & 0.040 & 8.7000 & 89.300 & 0.20000 & 1.20000 & -31.01000 \\
$\chi^{2}$ & 12.500 & 7.030 & $21.2800^{* *}$ & 3.090 & $87.13000^{* *}$ & $41.39000^{* *}$ & 267.19000 \\
$\mathrm{p}>\chi_{\mathrm{c}}^{2}$ & 0.013 & 0.134 & 0.0002 & 0.543 & 0.00001 & 0.00001 & 0.00001 \\
\hline
\end{tabular}

Bold = higher variance; underlined = lower variance; $\mathrm{VNH}=$ variance of the number of leaves; VAP = variance of plant height; VDT $=$ variance of diameter of cone; $\mathrm{VLH}=$ variance of leaf length; VAH = variance of leaf width; VNE = variance of number of spines; $\log \mathrm{D}=\log$ of the determinant

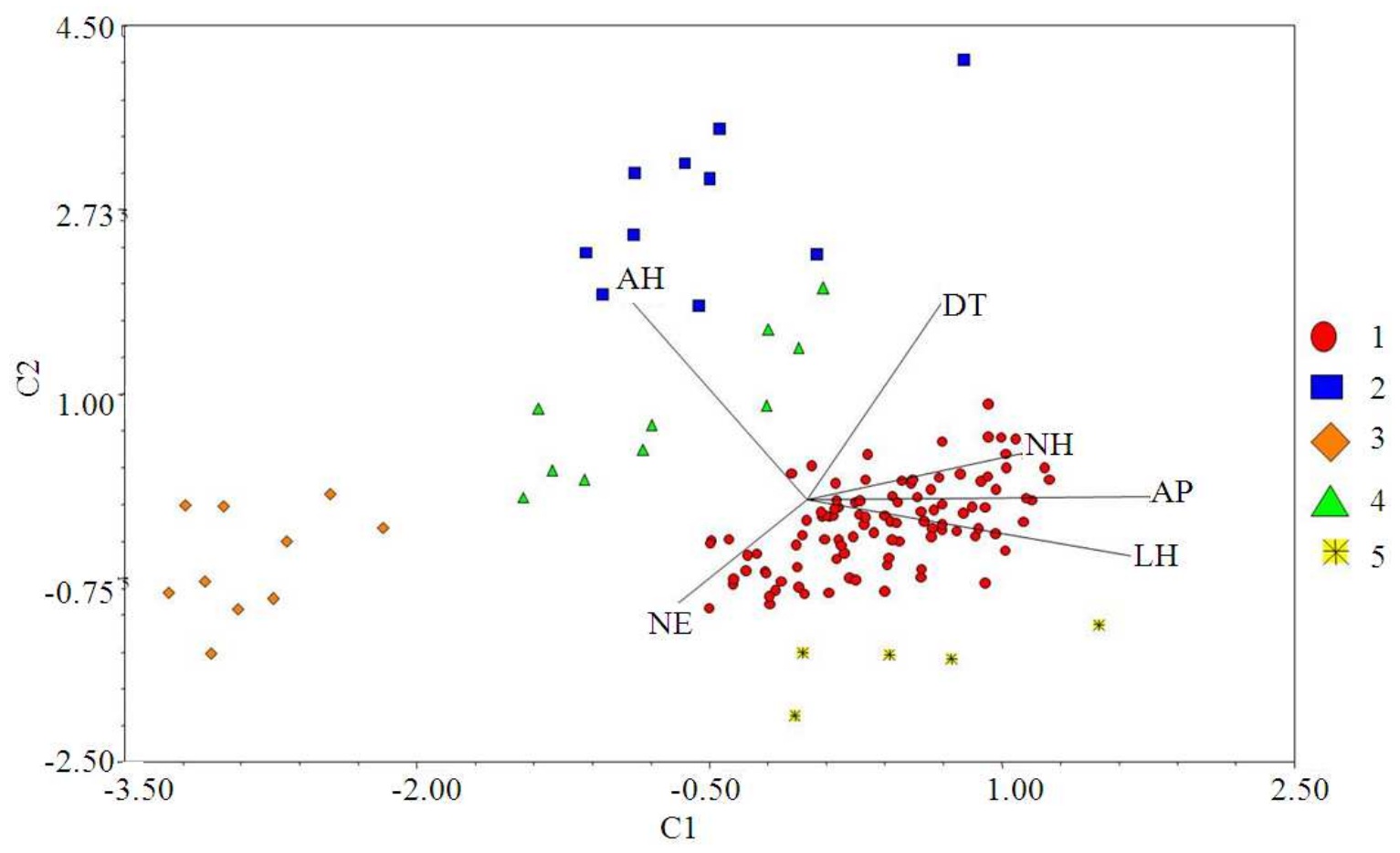

Fig. 3. Biplot of the principal components analysis for Agave spp. showing the vectors of the variables measured. 1: A. tequilana, 2: A. salmiana, 3: A. maximiliana, 4: A. americana, 5:A. angustifolia. $\mathrm{C} 1$ : first component, $\mathrm{C} 2$ : second component. $\mathrm{NH}$ : number of leaves, AP: plant height, DT: diameter of cone, LH: leaf length, AH: leaf width, NE: number of spines 


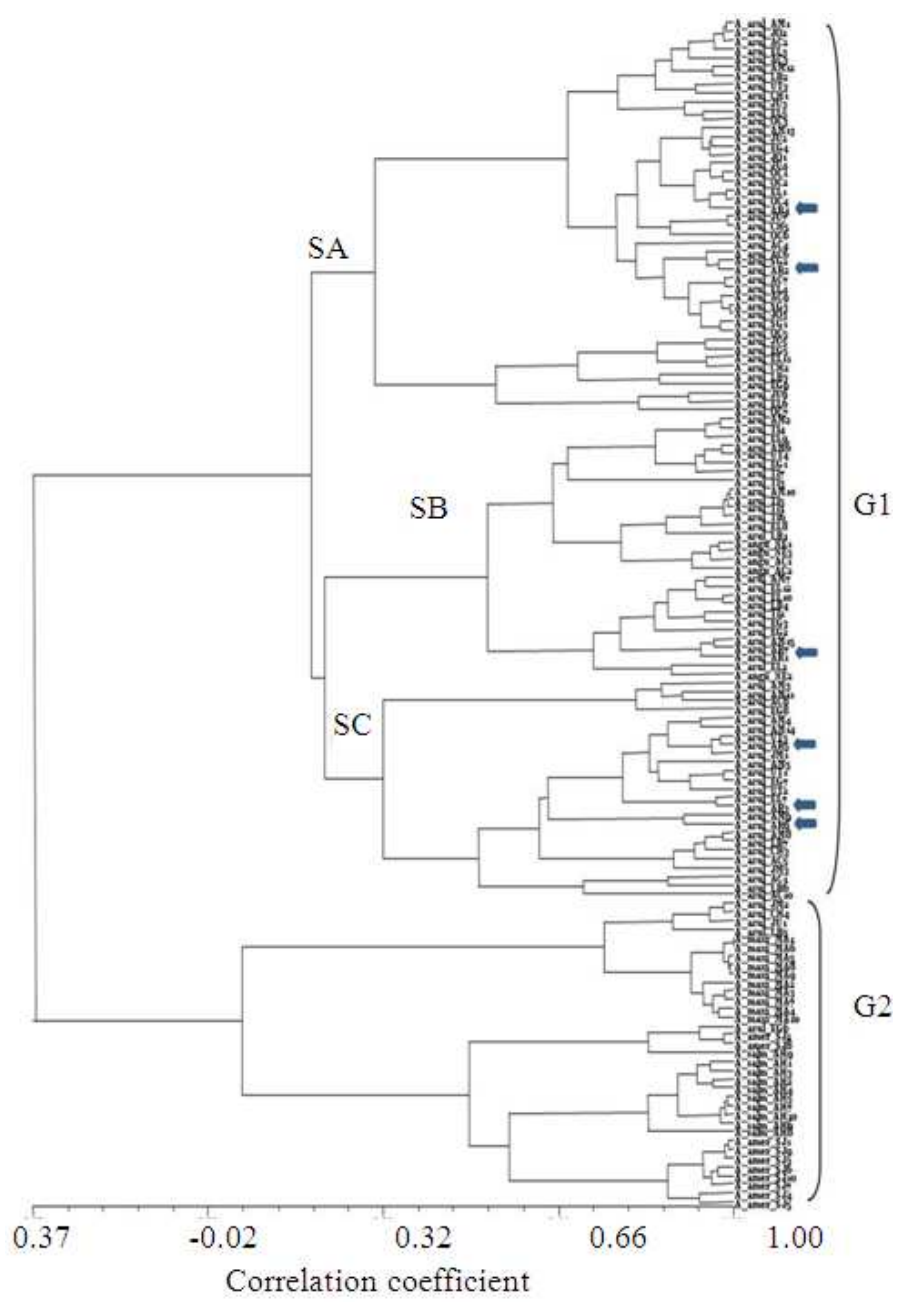

Fig. 4. Dendrogram generated by clustering analysis for five Agavaceae species based on morphological traits. G1: Group 1, G2: Group 2, SA: Subgroup A, SB: Subgroup B, SC: Subgroup C. Agave individuals collected from representative DOZ were marked with an arrow

In terms of the second Component (C2), A. salmiana differed with respect to AP and so its position in the biplot is opposite that of A. tequilana and A. angustifolia (see morphological differences in Fig. 2).

The cluster analysis divided the samples into two main groups (Fig. 4). The main division was that of $A$. tequilana and $A$. angustifolia from the other Agavaceae species. Subgroup SA was distinguished in the collections of $A$. tequilana and was characterized in individuals collected from the four regions of Jalisco, particularly in the southern zone (points 8, 9, 10, 11 and 14; Fig. 1). The dendrogram shows that specimens in subgroups SB and SC were grouped from different collection sites. The results indicate a high correlation between the morphological characters of $A$. tequilana from Tizapán el Alto, San Gabriel and Juchitlán, which do not belong to the main traditional culture areas (Tequila region and "Los Altos de Jalisco" region). Group 2 (G2, Fig. 4) contained the remaining groups of Agavaceae that were used to compare variability. In this group, A. maximiliana had lower average values for the variables $\mathrm{AP}, \mathrm{DT}, \mathrm{LH}$ and $\mathrm{AH}$ compared with $A$. salmiana and $A$. americana.

\subsection{Variability within Species}

Table 3 shows the variance estimates for the six variables studied. The highest variances were for $\mathrm{NH}$ in A. tequilana and A. salmiana. 
Martha Isabel Torres-Moran et al. / American Journal of Agricultural and Biological Sciences 8 (1): 44-53, 2013

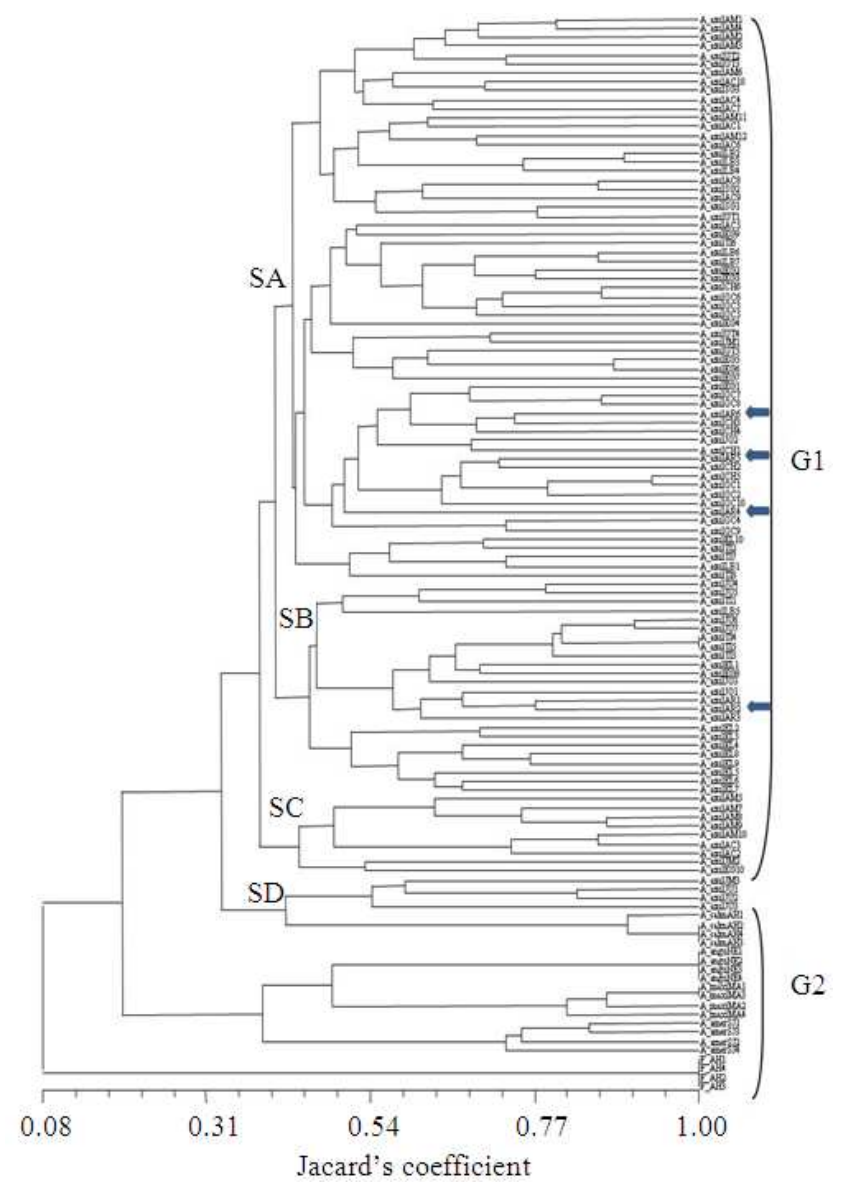

Fig. 5. Dendrogram generated by clustering analysis for six species of Agavaceae based on molecular data. G1: Group 1, G2: Group 2, SA: Subgroup A, SB: Subgroup B, SC: Subgroup C. Agave individuals collected from representative DOZ were marked with an arrow

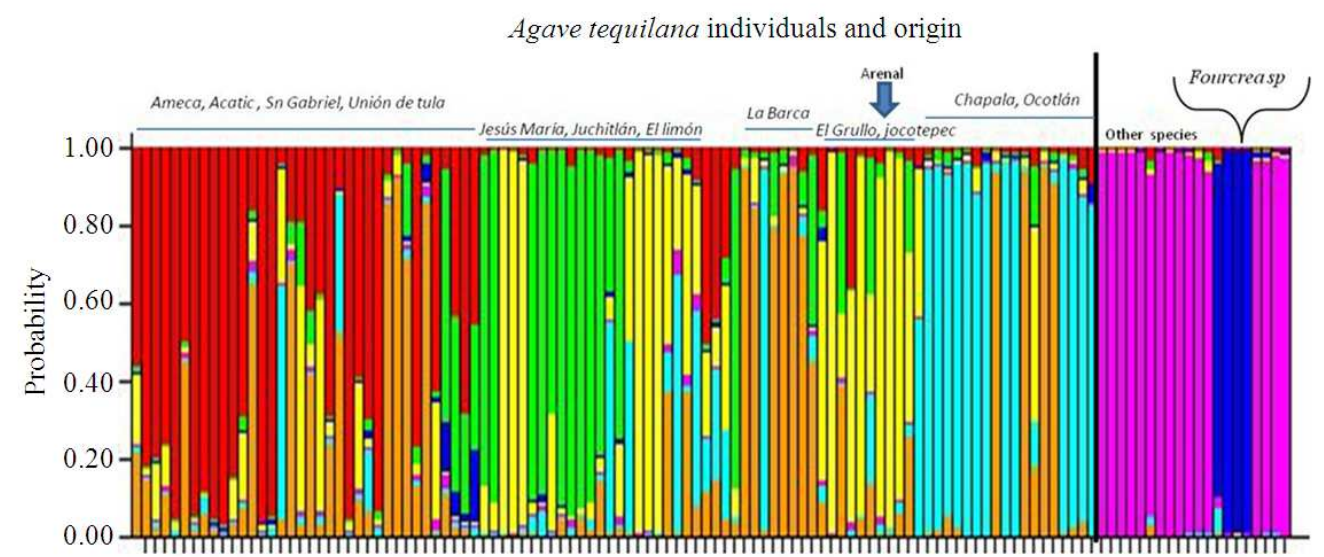

Genetic components of individuals

Fig. 6. STRUCTURE analysis using a simulation with $K=7$ for six species of Agavaceae 
There were major differences between species for DT, AH and NE. Values in Table 3 where $\chi^{2}>20$ were highly significant. The test for homogeneity of variance and the covariance matrix showed that the highest value for the logarithm of the determinant was in the A. salmiana group, which suggests high variability among individuals in this species. This can also be seen in the dispersion of dots representing these individuals in Fig. 3.

\subsection{Molecular Analysis}

The amplification patterns produced by the ISTR molecular marker were species-specific. A total of 53 bands were obtained and $94 \%$ were polymorphic. The similarity and clustering analysis based on molecular data detected a significant separation between Fourcrea spp. and the Agave group (Fig. 5) with a Jaccard's coefficient of 0.18 . The $A$. tequilana specimens were placed in a single Group (G1) on the dendrogram. The division of the subgroups within the principal group and the cluster analysis based on morphological data clearly demonstrate the genetic variability. Agaves are asexually propagated, but the differences in variability of the DNA were remarkable, with Jaccard's coefficient being as high as 0.40 . It is important to note the separation of four subgroups (SA, SB, SC and SD), which probably indicates the origins of the specimens.

\subsection{Genetic Structure}

The different species used in this study were separated by the analyses of molecular and morphological traits. In the genetic structure analysis using admixture-based models, each individual was assumed to have inherited some proportion of its genetic material from each of $K$ distinct populations. These proportions were determined as the admixture proportions for each individual and a key goal of these methods is to estimate the allele proportions and frequencies in each population (Engelhardt and Stephens, 2010). The genetic structure of 130 individuals of Agave based on the Bayesian-based model is shown in Fig. 6 for $K=7$. Evanno's method determined $\mathrm{K}=7$ as the most likely number of genetic clusters for the entire set of agave plants. The genetic structure indicated in Fig. 6 is in close agreement to geographic origin. Fourcrea spp were clearly separated from other Agavaceae members (Fig. 6). Agave tequilana individuals were subdivided into five groups by STRUCTURE, partly along geographic lines. We also calculated the proportion of variation within subpopulations (FST) relative to the total variation. The values were $>0.25$ in the external and comparison groups, indicating a very high differentiation in terms of allelic frequencies. The FST values ranged from 0.15 to 0.25 in $A$. tequilana, which also suggested high differentiation among individuals in this species.

Figure 6 shows the different $K$-simulated groups (in different colors). Among the A. tequilana specimens, it was possible to identify genetic differences that could explain the spread of genotypes among crop fields throughout the state and the DOZ. Accessions representing the sites of origin of Agave Azul, are indicated by arrows in Fig. 4-6.

\section{DISCUSSION}

This study suggests that genetic variability is present in asexually propagated plants, i.e., A. tequilana, as previously reported by other authors (Infante et al., 2003; Rodriguez-Garay et al., 2009; Torres-Moran et al., 2010; Esqueda et al., 2011). The differences between A. tequilana individuals collected from southern Jalisco state and those collected in the principal DOZ (Arenal, Acatic and Jesús María) confirmed the existence of different genotypes, which were conserved in specific regions by asexual propagation, as reported by Gil-Vega et al. (2001). The similarities between $A$. tequilana and $A$. angustifolia have been reported previously, which indicates that $A$. angustifolia is an ancestor of $A$. tequilana (Gentry, 1982; Davila et al., 2007; Vargas-Ponce et al., 2007). The current work clearly demonstrates the morphological and molecular differences between $A$. tequilana specimens and demonstrates the genetic variability within individuals of all the species examined. We detected differences within $A$. tequilana individuals and our study was conducted using a large sample (100 individuals), which contrasts with the small samples used in previous studies (Gil-Vega et al., 2001; 2006). The FST values indicate genetic differentiation within A. tequilana and $A$. angustifolia, as reported by Sanchez-Teyer et al. (2009). The model-based clustering method using multilocus genotype data based on ISTR molecular markers provided information on the population structure of A. tequilana and other Agavaceae species. The simulation program used $\mathrm{K}=7$ to produce a set of allele frequencies that probabilistically assigned each individual to a specific population, as reported by Pritchard et al. (2000). Morphological and molecular tools can detect genetic differences in plants that have previously been considered clonal individuals. These tools allowed us to estimate the relationship between Agave spp. and cluster in a group $A$. tequilana together with $A$. angustifolia, whereas a separate group was formed by $A$. maximiliana, 
A. americana, A. salmiana and Fourcrea spp. TorresMoran et al. (2010) have reported the separation of different agaves using ISTR. It is important to note that grouping based on genetic structure analysis shows relationships according to the dispersion of plant material from the initial sites of cultivation. It was indicated that the area of origin of Agave Azul is on the foothills of Colima volcanoes, near the Jalisco coast; from there, plants migrated along a geographical corridor up to the Tequila area, where Tequila beverage takes its name (Vargas-Ponce et al., 2009). Recently, following the commercial expansion, promoted interchange of plant materials into very distinct environments, enabling them to genotypic differentiation as seen in structure analysis.

\section{CONCLUSION}

In this study, we detected genetic variability within and among individuals and different species in the genus Agave. We used a large sample and this allowed us to detect different groups among field crops of the plant A. tequilana, which is propagated asexually. We also tested a mixture of samples from all localities in the DOZ. The differences we detected in A. tequilana could allow producers and industry to establish breeding programs by selecting elite phenotypes, while also preserving genetic resources by sustainable management in the immediate future.

\section{ACKNOWLEDGMENT}

The researchers wish to acknowledge Dr Ana Lília Guzmán Vigueras in the Departamento de Botánica y Zoología, Universidad de Guadalajara, for supporting the taxonomic identification of agaves in this work. To Dr. JJ Sanchez-Gonzalez for invaluable contribution.

\section{REFERENCES}

Cedeno, M.C. and J. Alvarez-Jacobs, 2000. Tequila Production from Agave. In: The Alcohol Textbook, Murtagh (Eds.), Nottingham University Press, Nottingham, UK.

Colunga-Garcia, P. and D. Zizumbo-Villareal, 2007. Tequila and other agave spirits from west-central Mexico: Current germplasm diversity, conservation and origin. Biodivers. Conserv., 16: 1653-1667. DOI: $10.1007 / \mathrm{s} 10531-006-9031-\mathrm{Z}$
Colunga-Garcia, P.M. and F. May-Pat, 1997. Morphological variation of henequen (Agave fourcroydes, Agavaceae) germplasm and its wild ancestor (A. angustifolia) under uniform growth conditions: Diversity and domestication. Am. J. Bot., 84: 1449-1465. DOI: 10.2307/2446608

Davila, M., M.A. Castillo and H. Laurentin, 2007. Uso de marcadores moleculares ISSR para inferir las relaciones geneticas y la variabilidad intraespecífico en Agave. Rev. Fac. Agron. (Maracay), 33: 93-111.

Demey, J.R., E. Gamez, S. Molina and D. Infante, 2004. Comparative study of the discriminating capacity of AFLP and ISTR markers for genetic analysis ofAgave fourcroydes. Plant. Mol. Biol. Rep., 22: 2935. DOI: $10.1007 / \mathrm{BF} 02773346$

Engelhardt, B.E. and M. Stephens, 2010. Analysis of population structure: A unifying framework and novel methods based on sparse factor analysis. PLoS Gen, 6: el00117-e100117. DOI: 10.1371/journal.pgen.1001117

Esqueda, M., A. Gutierrez, G. Palomino, A. GarciaMendoza and T. Terrazas, 2011. Morphological characterization and variation in the total content of reducing sugars in wild populations of Agave angustifolia Haw. Am. J. Agric. Biol. Sci., 6: 462468. DOI: 10.3844 /ajabssp.2011.462.468

Evanno, G., S. Regnaut and J. Goudet, 2005. Detecting the number of clusters of individuals using the software STRUCTURE: A simulation study. Mol. Ecol., 14: 2611-2620. DOI: 10.1111/j.1365294X.2005.02553.x

Gentry, H.S., 1982. Agaves of continental North America. University of Arizona Press, 1st Edn., Tucson, ISBN-10: 0816507759, pp: 670.

Gil-Vega, K., C. Diaz, A. Nava-Cedillo and J. Simpson, 2006. AFLP analysis of Agave tequilana varieties. Plant. Sci., 170: 904-909. DOI: 10.1016/j.plantsci.2005.12.014

Gil-Vega, K., M.G. Chavira, O.M.D.L. Vega, J. Simpson and G. Vandermark, 2001. Analysis of genetic diversity in Agave tequilana var. Azul using RAPD markers. Euphytica, 119: 335-341. DOI: 10.1023/A:1017553107303

Infante, D., G. Gonzalez, L. Peraza-Echeverria and M. Keb-Llanes, 2003. Asexual genetic variability in Agave fourcroydes. Plant. Sci., 164: 223-230. DOI: 10.1016/S0168-9452(02)00404-1

Infante, D.M., S. Molina and G. Gonzalez, 2007. Genetic improvement of asexually propagated plants. Acta Hort, 738: 721-727. 
Keb-Llanes, M., G. Gonzalez, B. Chi-Manzanero and D. Infante, 2002. A rapid and simple method for smallscale DNA extraction inAgavaceae and other tropical plants. Plant. Mol. Biol. Rep., 20: 299-299. DOI: $10.1007 / \mathrm{BF} 02782465$

Magdub-Mendez, A., 2000. Produccion mundial de henequen y sisal y su proyeccion a principios del siglo XXI. Agronomica, 1: 20-22.

Morrison, D.F., 1976. Multivariate Statistical Methods. 2nd Edn., McGraw Hill, ISBN-10: 0070431868, Tokyo, pp: 415.

Nei, M., 1978. Estimation of average heterozygosity and genetic distance from a small number of individuals. Genetics, 89: 583-590. PMID: 17248844

Piven, N.P., F.A. Barredo-Pool, I.C. Borges-Argaez, M.A. Herrera-Alamillo and A. Mayo-Mosqueda et al., 2001. Reproductive biology of henequen (Agave fourcroydes) and its wild ancestor Agave angustifolia (Agavaceae). I. Gametophyte development. Am. J. Bot., 88: 1966-1976.

Pritchard, J.K., M. Stephens and P. Donnelly, 2000. Inference of population structure using multilocus genotype data. Genetics, 155: 945-959.

Rawlings, J.O., 1988. Applied Regression Analysis. 1st Edn., Wadsworth and Brooks/Cole Advanced Books and Software, Pacific Grove, ISBN-10: 0534092462, pp: 553.

Rodriguez-Garay, B., J.A. Lomeli-Sencion, E. TapiaCampos, A. Gutierrez-Mora and J. Garcia-Galindo et al., 2009. Morphological and molecular diversity of Agave tequilana Weber var. Azul and Agave angustifolia Haw. var. Lineno. Ind. Crop. Prod., 29: 220-228. DOI: 10.1016/j.indcrop.2008.05.007

Rohlf, F.J., 1994. NTSYS-PC: Numerical Taxonomy and Multivariate Analysis System. 1st Edn., Exeter Software, Setauket, ISBN-10: 0925031224, pp: 7.

Sambrook, D.J. and D.D.W. Russell, 2001. Molecular Cloning: A Laboratory Manual. 3rd Edn., CSHL Press, Cold Spring Harbor, ISBN-10: 0879695773, pp: 2344.
Sanchez, G.J.J., 1995. El analisis Biplot en clasificacion. Rev. Fitotec. Mex., 18: 188-203.

Sanchez-Teyer, F., S. Moreno-Salazar, M. Esqueda, A. Barraza and M.L. Robert, 2009. Genetic variability of wild Agave angustifolia populations based on AFLP: A basic study for conservation. J. Arid. Environ., 73: 611-616. DOI: 10.1016/j.jaridenv.2009.01.008

Sanguinetti, C.J., E.D. Neto and A.J. Simpson. 1994. Rapid silver staining and recovery of PCR products separated on polyacrylamide gels. Biotechniques, 17: 914-921. PMID: 7840973

SASI, 1994. The SAS system for windows. SAS Institute Inc. Cary, NC 27513, USA.

Torres-Moran, M.I., M. Escoto-Delgadillo, S. MolinaMoret, D.M. Rivera-Rodriguez and A.P. VelascoRamirez et al., 2010. Assessment of genetic fidelity among Agave tequilana plants propagated asexually via rhizomes versus in vitro culture. Plant. Cell. Tiss. Org. Cult., 103: 403-409. DOI: 10.1007/s11240-010-9777-6

Vargas-Ponce, O., D. Zizumbo-Villarreal and P. Colunga-Garcia Marin, 2007. In situ diversity and maintenance of traditional Agave Landraces used in spirits production in West-Central Mexico. Econ. Bot., 61: 362-375. DOI: 10.1663/00130001(2007)61[362:ISDAMO]2.0.CO;2

Vargas-Ponce, O., D. Zizumbo-Villarreal, J. MartínezCastillo, J. Coello-Coello and P. Colunga-Garcia Marin, 2009. Diversity and structure of landraces of Agave grown for spirits under traditional agriculture: A comparison with wild populations of $A$. angustifolia (Agavaceae) and commercial plantations of $A$. tequilana. Am. J. Bot., 96: 448447. DOI: $10.3732 /$ ajb.0800176 